\title{
Pilot of a Low-Cost Elementary School Handwashing Intervention in Bangladesh: Acceptability, Feasibility, and Potential for Sustainability
}

\author{
Farhana Sultana, ${ }^{1 *}$ Leanne Unicomb, ${ }^{1}$ Mahbubur Rahman, ${ }^{1}$ Shahjahan Ali, ${ }^{1}$ Dorothy L. Southern, ${ }^{1}$ Dalia Yeasmin, ${ }^{1}$ \\ Rouha Anamika Sarkar, ${ }^{1}$ Kishor K. Das, ${ }^{1}$ Fosiul Alam Nizame, ${ }^{1}$ Peter J. Winch, ${ }^{2}$ and Stephen P. Luby ${ }^{3}$ \\ ${ }^{1}$ International Centre for Diarrhoeal Disease Research, Bangladesh (icddr,b), Dhaka, Bangladesh; ${ }^{2}$ Johns Hopkins Bloomberg School of Public \\ Health, Baltimore, Maryland; ${ }^{3}$ Stanford University, Stanford, California
}

\begin{abstract}
Schoolchildren frequently transmit respiratory and gastrointestinal infections because of dense person-toperson contact in schools. We piloted a low-cost handwashing intervention among elementary schoolchildren in Bangladesh. We trained teachers to lead behavior change communication sessions using flipcharts to encourage students' handwashing before eating, after defecating, and after cleaning school toilets; provided handwashing stations (reservoirs with taps and stool + basin + soapy water solution [mix of $30 \mathrm{gm}$ detergent with $1.5 \mathrm{~L}$ water] + pump top bottle with steel holder); and formed hygiene committees for maintenance and covering the recurrent cost of detergent. We evaluated intervention acceptability, feasibility, and potential for sustainability at 1 and 14 months after the intervention. At baseline, of 300 before eating events, no one washed hands with soap, and $99.7 \%$ (299) did not wash hands at all as soap was unavailable. Out of 269 after toileting events, $0.7 \%$ (2) washed hands with soap, and $88 \%$ (237) did not wash hands. After 4 weeks of the intervention, 45\% (87/195 before eating events), 83\% (155/186 after toileting events), and $100 \%$ (15/15 after cleaning toilet events) washed both hands with soapy water as children found it accessible, low cost, and child friendly. After 14 months, 9.4\% (55/586 before eating events) and 37\% (172/465 after toileting events) washed both hands with soapy water for health benefits. The intervention was acceptable and feasible; it overcame limited access to soap and water and was affordable as schools covered the recurrent costs of detergent. Further research should explore long-term habit adoption and impact on health and attendance.
\end{abstract}

\section{INTRODUCTION}

Elementary school children frequently transmit respiratory and gastrointestinal infections because of dense person-toperson contact in schools and poor hygiene conditions. ${ }^{1-3}$ Handwashing with soap can prevent diarrhea and respiratory illness; improving school attendance and academic performance. ${ }^{4-11}$ Handwashing behavior change has been repeatedly promoted to prevent the spread of SARS-CoV-2 infection; frequent handwashing (every 2 hours) was one of the measures used to avoid school closures in China, Denmark, Norway, Singapore, and Taiwan. ${ }^{12}$

To prevent the spread of respiratory and gastrointestinal infections, the U.S. Centers for Disease Control and Prevention and WHO recommend handwashing at important key times including before eating, after using toilet following five to seven steps: 1) wet hands with clean and running water and apply soap, 2) lather hands by rubbing them together with the soap, and lather the backs of hands, between your fingers, and under the nails, 3) scrub hands for at least 20 seconds, 4) rinse hands well with clean and running water, and 5) dry your hands using a clean towel or air dry them. ${ }^{13,14}$

Components of school-based handwashing interventions include the provision of tippy taps, Super Jaboncin (a cartoon superhero who fights germs using water and soap), sanitizer, and soapy water have been widely tested in low- and middleincome countries. ${ }^{15-21}$ Tippy taps provided a low-cost enabling technology, and increased handwashing rates, ${ }^{15,16}$ the use of sanitizer resulted reduced absenteeism, ${ }^{18,22}$ and the provision of soapy water reduced bar soap theft. ${ }^{20,23}$

\footnotetext{
*Address correspondence to Farhana Sultana, Environmental Interventions Unit, Infectious Diseases Division, International Centre for Diarrhoeal Disease Research, Bangladesh, 68 Shaheed Tajuddin Ahmed Sarani, Mohakhali, Dhaka 1212, Bangladesh. E-mail: farhana.sultana@icddrb.org
}

However, improving handwashing behaviors in schools in low- and lower-middle-income countries, including Bangladesh, has proven difficult to sustain as soap is expensive, schools lack funding and infrastructure, and soap placed at common handwashing stations may be stolen. ${ }^{24-26}$ Previous studies found the hands of elementary school children were less clean compared with older children in secondary schools in Bangladesh (27\% versus 49\%, $P<0.000) .{ }^{26-28}$

The National Standards for Water, Sanitation and Hygiene for Schools in Bangladesh 2011, the National Hygiene Promotion Strategy 2012, and the Ministry of Education Statement 2015 all aimed to increase handwashing in schools by providing soap and running water, improving handwashing behavior, operationalizing cleaning and maintenance routines, and creating school-based funding mechanisms. ${ }^{29,30}$ However, a weak and complicated budgetary allocation and procurement process in Bangladeshi schools fails to ensure an operating budget for basic supplies, including soap. ${ }^{31,32}$ Most of the studies on handwashing behavior change are short-term and do not assess the prolonged habit adoption after the intervention period, ${ }^{33}$ though this is a key consideration for costeffectiveness and sustainability. We developed and pilot-tested a low-cost handwashing intervention to provide practical infrastructure, affordable supplies, and a pathway to institutionalize improved hygiene practices. We also collected long-term postintervention follow-up data on handwashing uptake to assess prolonged and sustained habit adoption. This article describes school children's baseline knowledge, practices, perceptions, motivations, and barriers of hand hygiene, and the effectiveness, acceptability, feasibility, and potential for sustainability of a school handwashing intervention.

\section{MATERIALS AND METHODS}

Study setting and study participants. The essential elements of the study have been described previously. ${ }^{26}$ 
Briefly, we conducted this study among four urban and four rural elementary school students (both government and nongovernment) in Bangladesh from May 2011 to September 2013. This was a proof-of-concept study that we conducted in multiple phases (Supplemental Table 1) as described below in more detail.

Phase 1: Formative study of current knowledge, practices, perceptions, motivations, and barriers. Out of eight schools, two urban and two rural schools participated in the formative study from September to November 2011. The purpose of the formative study was to identify and develop an intervention that is feasible, acceptable with the potential to be sustainable at improving handwashing with soap. We explored student-friendly technological options for handwashing stations, the most effective participatory implementation process with the best suited channel(s) of communication and operationalize and maintenance methods to make consistent the use of the preferred set of interventions.

Spot checks of facilities. Fieldworkers conducted spot checks of baseline water, sanitation, and hand hygiene facilities (Supplemental Appendix 1a and 1b) in each of the four schools to explore the factors in the physical environment favoring or discouraging handwashing with soap before eating and after toileting or after a respiratory related condition (Table 3).

Structured observations. Fieldworkers conducted a 4-hour long structured observation on three consecutive days to explore students' baseline hand hygiene practices. We prepared a standard hand hygiene behavior assessment tool to observe and record hand hygiene practices of each student. Fieldworkers informed school administrators, but not individual students, about the purpose of the visit. They placed themselves in a convenient place at each school compound and noted any hand hygiene behavior related events on the pre-coded structured observation form.

Baseline student survey. A previous study conducted by UNICEF found $10 \%$ of Bangladeshi schoolchildren washed hands after defecation at baseline and 35\% after handwashing intervention. A sample of 102 students would provide $80 \%$ power and $95 \%$ confidence with design effect of 2 to account for clustering. We increased the targeted number of students to 200 to provide greater power given clustering by school and class. We randomly selected 50 students from each school. The schools averaged 475 students. Fieldworkers prepared a list of all students from grades 4 and 5 using class registers and then randomly drew 25 names from an envelope from each grade.

Qualitative interviews. We purposively selected participants for in-depth interviews and focus group discussions based on the objective of the study, students' enrolment in grades 4 and 5 , and availability and willingness to participate. Fieldworkers conducted 16 in-depth interviews and 12 focus group discussions with the head, science and assistant teachers, school management committee and parentteacher association members, janitors, male and female students, and female students to gather information related to perceptions on hygiene-related topics, suggestions for the design and content of the set of interventions, and the process of implementation. We crosschecked findings from different methods to increase validity.

Participatory exercises. Fieldworkers conducted 12 drawing, vignette, ranking, and puzzle exercises with purposively selected students to explore and identify what attributes they wanted in an ideal handwashing station and their perception of symptoms and signs of diarrhea. These participatory techniques were designed to be child friendly, nonthreatening, and facilitating the expression of views by the child, without adults being involved. ${ }^{34,35}$ For example, we explored the use of artwork/drawings with the children to help them express their ideas more easily and to investigate what attributes they want in an ideal toilet. We applied vignette approaches to explore their perception of symptoms and signs of diarrhea and respiratory diseases and the routes of transmission and understand social norms related to these diseases. We provided the cards depicting a variety of symptoms and asked to match the symptoms to the illnesses. To understand the children's preferred option for handwashing stations and motivators, we used ranking and puzzle exercise by displaying colorful pictures and cartoon illustrations. During the discussions, we presented options stating the advantages and disadvantages in light of their environmental context. Through the discussion, we obtained an idea on the preferred intervention option by asking each child to place a colored stone on the most preferred option for each of our category of options that they would like to see in their school grounds. At the end of the discussion, the number of stones was counted in each category and the reasons for their choices discussed.

Intervention development and trial of improved practices. We organized an intervention development workshop with teachers, school management committee members, and coauthors (F. S., L. U., F. A. N., S. A., and P. W.) to seek feedback on a feasible handwashing intervention.

Based on the findings from Phase1, we developed an on-site school intervention that included 1) training teachers to lead behavior change communication sessions using 12 $\times 17$-inch pictorial flipcharts and cue cards (Supplemental Figure 1); 2) provision of two handwashing stations: bucket with taps $+10 \mathrm{~L}$ bucket as basin + soapy water bottle containing a low-cost solution of $\mathbf{3 0} \mathrm{gm}$ detergent powder mixed with water in a 1.5-L pump top bottle + steel holder (Supplemental Table 2); and 3) formation of a hygiene committee of students, teachers, janitors, parents, and school management committee members to maintain the handwashing stations, pay for the detergent cost, promote regular hand hygiene practices, and overcome the weak accountability for allocation of budget line items to essential supplies.

To train the schoolteachers, we invited them to International Center for Diarrheal Disease Research, Bangladesh (icddr,b) and held a1-day training on how to conduct sessions, deliver messages using flipcharts and maintain the handwashing stations. This training of teachers aimed to create a resource person in schools to promote cough etiquette practices, to deliver communication sessions, and to ensure ownership of the project for long-term sustainability of cough etiquette behavior change.

The flipcharts entailed detailed discussion on topics related to 1) importance of healthy life and regular school attendance, 2) impact of unhygienic practices on health and school attendance, 3) route of disease transmission, 4) healthy hands, 5) barriers to handwashing with soap in school, 6) introduction of the handwashing stations, 7) soapy water preparation method, 8) important key times/antecedents of handwashing, 9) handwashing steps adapted from $\mathrm{CDC}$ and $\mathrm{WHO}$, and 10) maintenance of the handwashing 
stations. The cue card identified important key times behavioral antecedents for handwashing.

The purpose of the hygiene committee was to ensure ownership/leadership of the project for long-term sustainability of handwashing behavior change, and to help the school community decide on implementation process, and on methods to fund the recurrent cost of soap, cleaning materials, and associated maintenance cost. The committee consisted of 18 members: 10 students of grade 4 and 5 (as members to monitor and support the maintenance of the handwashing stations), one head and two assistant teachers (as secretary and assistant secretary to conduct sessions and ensure funds), two education officials (as advisor and coadvisor to monitor and guide the intervention activities), one janitor (as supportive staff to maintain the handwashing stations), and one school management committee and one parent-teacher association members (as chair and cochair to support funds) in each school.

We then conducted a 2-week trial of improved practices, ${ }^{36}$ to pretest the intervention materials in each four of the baseline formative schools. We then conducted structured interviews with eight teachers and 100 students to explore the appropriateness, feasibility, and acceptability of these interventions in the school communities.

Phase 2: Piloting the intervention for acceptability and feasibility. We piloted the intervention in the remaining four schools in June 2012. The purpose of the pilot phase was to evaluate and assess the acceptability and feasibility of the intervention in terms of uptake of target practices through the outcomes of increased knowledge of key times to wash hands with soap, perceived barriers of handwashing and perceived subjective and descriptive norms for handwashing.

Spot checks of facilities. Fieldworkers conducted spot checks of handwashing facilities (Supplemental Appendix 1a and $1 b$ ) before and after intervention rollout to explore if the improvement in the physical environment (provision of handwashing stations) favoring or discouraging handwashing with soapy before eating, and after toileting and after cleaning toilet (Table 3). We demonstrated the use of soapy water and handwashing stations, forming the hygiene committee, and training teachers to lead, deliver, and continue behavior change communication sessions in conjunction with the existing weekly hygiene classes. We assessed the intervention 4 weeks after the commencement of the sessions in July 2012.

Structured observations. Fieldworkers monitored the intervention for 1 month by conducting a 4-hour long structured observation on six occasions (days 1, 2, 3, 7, 14, and 30) after the first class on hand hygiene commenced.

Qualitative assessment. Fieldworkers conducted qualitative interviews to explore the acceptability and feasibility of the intervention. We purposively selected a variety of stakeholders and students based on their availability and willingness to participate. Fieldworkers conducted two in-depth interviews with the janitors at urban schools and 14 focus group discussions (four each with students of grade 4 and 5 who were observed to wash hands, with those who were observed not to wash hands, teachers, school management committee, and parent-teacher association members, and two with the student members of hygiene committee at rural schools.

Phase 3: Follow-up assessment at 14 months to explore sustainability. The purpose of this phase was to explore the potential for sustainability of the intervention through understanding variations in uptake and practices and determining facilitating and inhibiting factors for handwashing and the various intervention components are perceived by the school community. Fieldworkers revisited pilot intervention schools in August 2013, 14 months after the intervention commenced, and 13 months after the study staff withdrew.

Spot checks of facilities. Fieldworkers conducted four spot checks of facilities (Supplemental Appendix 1a and 1b) in each of the four schools to explore if the handwashing stations that we provided during the pilot testing phase of the study were in use and maintained by the hygiene committee (Table 3).

Structured observations. They also conducted 4-hour structured observations of students using a checklist for three consecutive days to identify students who washed or did not wash hands.

Focus group discussions. Fieldworkers conducted 12 focus group discussions with the purposively selected students of grades 4 and 5 who washed and did not wash hands, and with the teachers, school management committee, and parent-teacher association members to understand their perceptions, perceived benefits, and barriers of handwashing with soapy water.

Data collection and analysis. We collected both qualitative and quantitative data using a baseline survey, follow-up observations of uptake, and qualitative assessments.

All the observations were made on the school premises, and the interviews were conducted in Bengali in classrooms during school hours and lunch breaks. We structured our study questionnaires and findings using the integrated behavioral model for water, sanitation, and hygiene (IBMWASH) framework adapted for school WASH interventions ${ }^{37}$ to determine the influential behavioral factors (Table 1). Detailed analysis using different factors of this model in this study have been described previously. ${ }^{26}$ Briefly, the model describes 1) contextual dimension-the social and physical environment in which the WASH behaviors and technologies are implemented; 2) a psychosocial "software" dimension-social and psychological factors that affect WASH practices; and 3) a technological "hardware" dimension factors affecting adoption of WASH technologies. In this study, the contextual dimension represents the formative study findings that we used to develop the intervention package. The psychosocial (e.g., the behavior change communication strategies) and technological (e.g., handwashing stations) dimension represents the findings after the intervention was implemented (Table 1).

For quantitative data analysis, we performed a descriptive summary of socio-demographic characteristics, and reported student survey data that included investigating the IBMWASH model (knowledge, practice, beliefs, subjective and descriptive norms, access to facility and self-efficacy of promoted hygiene behaviors). We compared the proportion of observed hand hygiene practices before eating, after toileting and after cleaning school toilet at baseline, pilot, and 14 months follow-up using cluster adjusted Pearson's $\chi^{2}$ test. $^{38}$

Trained fieldworkers transcribed the audiorecorded focus group discussion and in-depth interview data and then translated it into English. We prepared the interview guideline based on research objectives and conducted a thematic content analysis to provide descriptive and systematic 


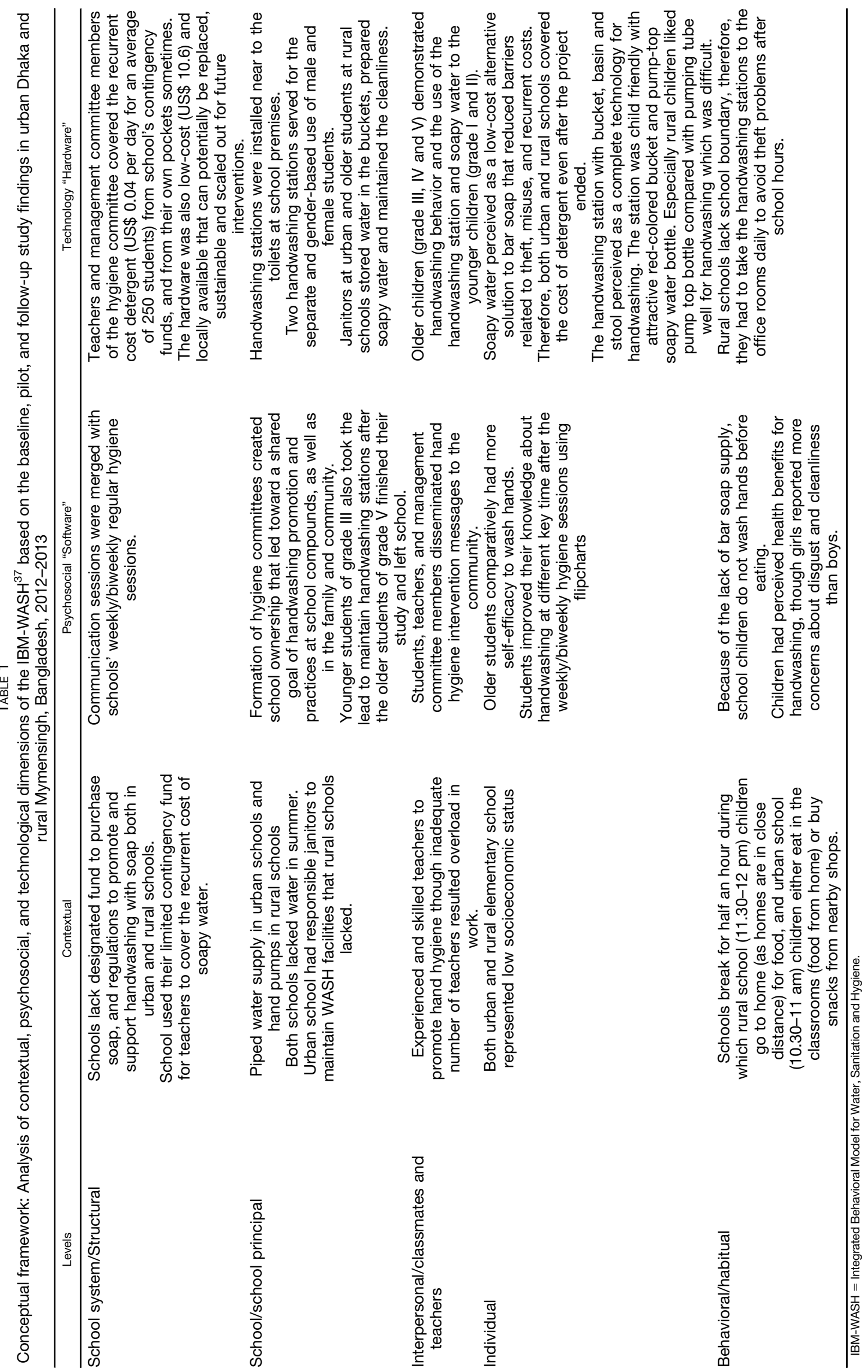


results. We analyzed each in-depth interview and each focus group discussion separately; however, we have drawn inferences collectively from both types of data and presented these in the results.

Ethics. We obtained permission from the Government of Bangladesh Divisional Primary Education Office, Dhaka, to work in specific schools in Dhaka and Mymensingh districts for research purposes. All teachers provided written consent, and students assented to participate before we collected data from them. The icddr,b Ethical Review Committee reviewed and approved the study protocol.

\section{RESULTS}

School participants. Most study respondents were students of grades 4 and 5 with a mean age of 10.1 years old (SD 1.3) (Table 2).

Phase 1: Formative study of knowledge, practices, perceptions, motivations, and barriers. Spot checks of facilities showed that only one urban school had a separate handwashing station; this station had intermittent piped water into a broken basin next to the toilet. For both rural schools, the area surrounding the outdoor tube well areas served as the handwashing stations. Soap was not present in any of the four schools (Table 3).

During the structured observations, fieldworkers observed 569 student opportunities for handwashing: 53\% (300) before eating and $47 \%$ (269) after toileting. In the 300 handwashing opportunities before eating, none of the children washed hands with soap, and 99.7\% (299) did not wash hands at all. Among the 269 handwashing opportunities after toileting, $0.7 \%$ (2) children washed hands with soap, and 88\% (237) did not wash hands at all (Table 4).

In the 200 student survey, 95\% (190) of students reported that handwashing with soap and water reduces diarrhea, $94 \%$ (189) reported washing hands before eating, and $85 \%$
(171) after toileting. However, 100\% (199) noted the lack of soap and a specific place to wash hands at school (Table 5).

During the in-depth interviews, rural students reported using soil to clean their hands after defecation, and urban students reported washing their hands with water only as no soap was available. Some students noted that teachers kept some soap in their room, but it was not commonly available to students.

One male student of grade 4 at an urban school said: I think teachers will scold me if I go to collect bar soap from their room, so I wash hands with water only and dry them with my school uniform.

One female student of grade 5 at a rural school said: We feel bad to rub our hands with soil after toileting.

Teachers and school management committee members noted they lacked school funds to purchase soap, and theft and misuse of bar soap were barriers to providing soap for students to wash their hands. Although the urban schools had a separate location for handwashing with piped water and a basin next to the toilet, the unavailability of soap was a barrier for handwashing. Rural schools did not have a separate location for handwashing, nor even a stored water reservoir inside the toilet. Students used a bodna (small jug) to collect water from the tube well or nearby pond during summer.

One female head teacher at an urban school said: We don't have money particularly to buy soap. Even if we provide, students play football with the soap, so I stopped providing.

One male head teacher at a rural school said: We were keeping soap, but the rats were taking them away frequently.

During the participatory exercises, most of the students identified vomiting and headache as diarrheal disease symptoms, ranked comfort, disgust, and social acceptance as motivators (Supplemental Figure 2), and drew both soap and water together as basic amenities for handwashing at school compounds.

TABLE 2

Socio demographic characteristics of study respondents in urban Dhaka and rural Mymensingh, Bangladesh, 2012-2013

\begin{tabular}{|c|c|c|c|}
\hline Indicators & $\begin{array}{l}\text { Baseline study } \\
n(\%)\end{array}$ & $\begin{array}{l}\text { Pilot testing of intervention } \\
n(\%)\end{array}$ & $\begin{array}{l}\text { 14-month follow-up assessment } \\
n(\%)\end{array}$ \\
\hline \multicolumn{4}{|l|}{ Respondent characteristics } \\
\hline Student & $248(89)$ & $144(86)$ & $24(50)$ \\
\hline Female & $139(56)$ & 77 (53) & $12(50)$ \\
\hline Adults & $30(11)$ & $24(14)$ & $24(50)$ \\
\hline Female & 07 (23) & 08 (33) & $08(33)$ \\
\hline \multicolumn{4}{|l|}{ Mean age (years) of respondent } \\
\hline Student & 11 & 11 & 10 \\
\hline Adults & 41 & 38 & 40 \\
\hline \multicolumn{4}{|l|}{ Education of the respondent } \\
\hline Grade III & 0 & $2(1)$ & 0 \\
\hline Grade IV & $124(45)$ & $82(48)$ & $14(29)$ \\
\hline Grade V & $124(44)$ & $62(37)$ & $12(25)$ \\
\hline Elementary & $6(2)$ & $6(4)$ & $4(8.3)$ \\
\hline Secondary & $9(3)$ & 0 & $3(6.2)$ \\
\hline Tertiary & $7(3)$ & $8(5)$ & $5(10)$ \\
\hline Graduation & $8(3)$ & $8(5)$ & $10(21)$ \\
\hline \multicolumn{4}{|l|}{ Occupation of the guardian of the students } \\
\hline Farmer & 49/248 (20) & $17 / 144$ (12) & $5 / 24(21)$ \\
\hline Salaried Gov. job & $39 / 248$ (16) & $20 / 144$ (14) & $5 / 24(21)$ \\
\hline Small business & $68 / 248(27)$ & $71 / 144$ (49) & $7 / 24(29)$ \\
\hline Nonagricultural labor/Rickshaw puller & 50/248 (20) & 20/144 (14) & $5 / 24(21)$ \\
\hline Other ${ }^{*}$ & $42 / 248(17)$ & $16 / 144(44)$ & $2 / 24(8)$ \\
\hline
\end{tabular}

*Day labor, driver, mason, mechanic carpenter, living abroad, gas contractor and bus helper. 
TABLE 3

Schools physical environment and spot checks of handwashing facilities at baseline, pilot, and follow-up in elementary schools in urban Dhaka and rural Mymensingh, Bangladesh, 2012-2013

\begin{tabular}{|c|c|c|c|c|c|c|c|c|}
\hline \multirow[b]{2}{*}{ Indicators } & \multicolumn{2}{|c|}{ Urban government school } & \multicolumn{2}{|c|}{$\begin{array}{c}\text { Urban registered } \\
\text { nongovernment school }\end{array}$} & \multicolumn{2}{|c|}{ Rural government school } & \multicolumn{2}{|c|}{$\begin{array}{c}\text { Rural registered } \\
\text { Nongovernment school }\end{array}$} \\
\hline & Formative & Pilot & Formative & Pilot & Formative & Pilot & Formative & Pilot \\
\hline \multicolumn{9}{|c|}{ Schools' physical environment and handwashing facilities at baseline } \\
\hline \multicolumn{9}{|c|}{ Total number of students } \\
\hline $200-500$ & 0 & 0 & 1 & 0 & 1 & 1 & 1 & 1 \\
\hline $600-1100$ & 1 & 1 & 0 & 1 & 0 & 0 & 0 & 0 \\
\hline $\begin{array}{l}\text { Total number of } \\
\text { toilets }\end{array}$ & 2 & 4 & 1 & 1 & 1 & 1 & 1 & 1 \\
\hline \multicolumn{9}{|c|}{ Source of water for handwashing } \\
\hline $\begin{array}{l}\text { Piped water } \\
\text { supply }\end{array}$ & 1 & 1 & 0 & 0 & 0 & 0 & 0 & 0 \\
\hline Deep tube well & 0 & 0 & 1 & 1 & 0 & 0 & 0 & 0 \\
\hline $\begin{array}{l}\text { Shallow tube } \\
\text { well }\end{array}$ & 0 & 0 & 0 & 0 & 1 & 1 & 1 & 1 \\
\hline \multicolumn{9}{|c|}{ Type of handwashing facility } \\
\hline Basin & 1 & 0 & 0 & 0 & 0 & 0 & 0 & 0 \\
\hline Toilet area & 0 & 1 & 1 & 1 & & & & \\
\hline Tube well area & 0 & 0 & 0 & 0 & 1 & 1 & 1 & 1 \\
\hline $\begin{array}{l}\text { Water at the } \\
\text { handwashing } \\
\text { station }\end{array}$ & 0 & 1 & 0 & 0 & 1 & 1 & 0 & 0 \\
\hline $\begin{array}{l}\text { Soap/hand } \\
\text { cleansing } \\
\text { material at the } \\
\text { handwashing } \\
\text { station }\end{array}$ & 0 & 0 & 0 & 0 & 0 & 0 & 0 & 0 \\
\hline $\begin{array}{l}\text { Handwashing } \\
\text { facilities after } \\
\text { the intervention }\end{array}$ & Pilot & Follow-up & Pilot & Follow-up & Pilot & Follow-up & Pilot & Follow-up \\
\hline \multicolumn{9}{|c|}{ Availability of handwashing facilities/intervention materials } \\
\hline Water & 1 & 0 & 1 & 1 & 1 & 1 & 1 & 1 \\
\hline Soapy water & 1 & 0 & 1 & 1 & 1 & 1 & 1 & 1 \\
\hline $\begin{array}{l}\text { Detergent } \\
\text { powder }\end{array}$ & 1 & 0 & 1 & 0 & 1 & 1 & 1 & 1 \\
\hline Metal holder & 1 & 0 & 1 & 1 & 1 & 1 & 1 & 1 \\
\hline Flipcharts & 1 & 1 & 1 & 1 & 1 & 1 & 1 & 1 \\
\hline Cue cards & 1 & $1 \dagger$ & 1 & 1 & 1 & $1 \dagger$ & 1 & $1 \neq$ \\
\hline $\begin{array}{l}\text { Functionality } \\
\text { of the } \\
\text { handwashing } \\
\text { stations }\end{array}$ & 1 & 1 & 1 & 1 & 1 & 1 & 1 & 1 \\
\hline $\begin{array}{l}\text { Weekly hygiene } \\
\text { sessions } \\
\text { continued }\end{array}$ & 1 & $0 \ddagger$ & 1 & $0 \ddagger$ & 1 & 1 & 1 & 1 \\
\hline
\end{tabular}

Phase 2: Piloting the intervention for acceptability and feasibility. The spot checks of facilities found the handwashing stations that the project had provided were functional and filled with soapy water after the intervention was implemented (Table 3).

During the structured observations, fieldworkers observed 396 students' opportunities for handwashing: 49\% (195) before eating, $47 \%$ (187) after toileting, and 4\% (15) after cleaning the toilet. In the 195 handwashing opportunities before eating, $45 \%$ (87) of children washed both hands with soapy water; $55 \%$ (108) did not wash hands at all. In the 186 handwashing opportunities after toileting, 83\% (155) of children washed both hands with soapy water (Table 4).

During the qualitative assessment, students who were observed to wash hands reported both physical and psychological health benefits of handwashing that provided germfree hands, a good feeling with clean hands, and more school attendance with more opportunities to play with friends.

One female student of grade 5 at an urban school said: I felt disgusted while I could not wash hands before the intervention. Now, every time I wash my hands with soapy water after using the school toilet, it makes me feel that my hands are clean and germ-free.

By contrast, students who were observed not to wash hands tended to pretend that they washed hands during the interviews. Some of them believed that germs are invisible and can never be removed by washing hands.

All the students, teachers, parents, and school management committee members reported that the handwashing stations were attractive, easy to use, child friendly, and visually reminded them to wash their hands. They also mentioned that soapy water was a low-cost option of providing water and soap together. Students said they shared the idea 
TABLE 4

Proportion of observed hand hygiene practices before eating, after toileting, and after cleaning toilet at baseline, pilot, and follow-up in urban Dhaka and rural Mymensingh, Bangladesh, 2012-2013

\begin{tabular}{|c|c|c|c|}
\hline Indicators & Baseline formative study & Pilot testing of the intervention & 14-month follow-up assessment \\
\hline Before eating & $N=300$ & $N=195$ & $N=586$ \\
\hline Washing hands using water only \% (n) & $0.3(1)$ & 0 & $0.9(5)$ \\
\hline Washing both hands using soap/soapy water \% (n) & $0.0(0)$ & $45(87)^{\star}$ & $9(55)^{\star}$ \\
\hline Ate with spoon \% $(n)$ & 0 & 0 & $1(6)$ \\
\hline Did not wash hands at all \% (n) & 99.7 (299) & $55(108)^{\star}$ & $89(520)$ \\
\hline After toileting & $N=269$ & $N=186$ & $N=465$ \\
\hline Washing hands using water only \% $(n)$ & $11.2(30)$ & 0 & $25(118)^{\star} \dagger$ \\
\hline Washing both hands using soap/soapy water \% (n) & $0.7(2)$ & $83(155)^{\star}$ & $37(172)^{\star}$ \\
\hline Did not wash hands at all \% (n) & $88(237)$ & $17(31)^{\star}$ & $38(175)$ \\
\hline After cleaning toilet $\ddagger$ & & $N=15$ & $N=4$ \\
\hline Washing hands using water only \% (n) & 0 & 0 & 0 \\
\hline Washing both hands using soap/soapy water \% (n) & 0 & $100(15)$ & $50(2)$ \\
\hline Did not wash hands at all \% $(n)$ & 0 & $0(15)$ & $50(2)$ \\
\hline
\end{tabular}

* Proportion is significantly different compared with baseline formative study using clustered $\chi^{2}$ test, $P$ value $\leq 0.05$.

†Proportion is significantly different compared with pilot testing study using clustered $\chi^{2}$ test, $P$ value $\leq 0.05$.

$\ddagger$ No statistical test was conducted because of small sample size.

with their family. They perceived that fixing cue cards in school compounds and viewing the pictorial flipcharts in hygiene classes were good ways to impart knowledge.

One female student of grade 5 said: The $10 \mathrm{~L}$ bucket (basin) contains waste handwashing water that looks really dirty. We never saw it when we washed our hands before, and the wastewater drained away. Now we can understand how dirty our hands were.

One male student of grade 5 at a rural school said: Now we have all the things (water and soap) in one place: just

TABLE 5

Reported knowledge, practices, perceptions and barriers related to handwashing using closed-ended questions during the baseline formative study in urban Dhaka and rural Mymensingh, Bangladesh, 2012-2013

\begin{tabular}{|c|c|}
\hline Indicators & $\begin{array}{c}N=200 \\
\%(n)\end{array}$ \\
\hline \multicolumn{2}{|l|}{ Perceived knowledge } \\
\hline Believe that not washing hands causes diarrhea & $56(1)$ \\
\hline $\begin{array}{l}\text { Believe that not washing hands with soap and } \\
\text { water after defecation causes diarrhea }\end{array}$ & $66(3)$ \\
\hline $\begin{array}{l}\text { Believe that not washing hands with water } \\
\text { regularly causes diarrhea }\end{array}$ & $10(0.5)$ \\
\hline $\begin{array}{l}\text { Believe that washing hands with soap and water } \\
\text { before eating causes less diarrhea }\end{array}$ & $190(9)$ \\
\hline Reported handwashing practices & - \\
\hline With water only & $127(6)$ \\
\hline With water and soap & $31(1)$ \\
\hline With water and ash & $1(0.5)$ \\
\hline With water and mud & $40(2)$ \\
\hline \multicolumn{2}{|l|}{ Perceived barriers of handwashing } \\
\hline Lack of a specific place & $199(9)$ \\
\hline Intermittent/unavailable water supply & $59(3)$ \\
\hline Lack of soap & $180(9)$ \\
\hline \multicolumn{2}{|l|}{ Most common reason for the unavailability of soap } \\
\hline Lack of funds to purchase soap & $107(5)$ \\
\hline Bar soap get used up quickly & 19 (1) \\
\hline School students steal soap & $6(0.3)$ \\
\hline Teachers kept bar soap locked up & $3(0.1)$ \\
\hline \multicolumn{2}{|l|}{$\begin{array}{l}\text { Perceived subjective and descriptive norms for } \\
\text { handwashing }\end{array}$} \\
\hline $\begin{array}{l}\text { Feeling of strong obligation to wash hands every } \\
\text { time after defecation }\end{array}$ & $156(7)$ \\
\hline $\begin{array}{l}\text { Teachers, parents, and friends approve washing } \\
\text { hands }\end{array}$ & $142(7)$ \\
\hline $\begin{array}{l}\text { Encouragement by teachers and friends can } \\
\text { increase handwashing practices }\end{array}$ & $187(9)$ \\
\hline
\end{tabular}

have to pump the bottle to get soapy water and turn on the tap to get water from the bucket to wash hands.

One female school management committee at a rural school said: Actually, it is a good initiative (the intervention) to keep the children clean and hygienic.

Teachers and management committee members of the hygiene committee formed a fund at each school and reported that they decided to contribute US\$0.25 to 1.25 each month for purchasing low-cost detergent powder (US\$0.75) per sachet for daily use or $1-\mathrm{kg}$ pouch bags for longer use. Since the detergent powder was low cost, the head teachers at each school mainly covered such costs from contingency funds and/or their own pockets. They also mentioned that the formation of hygiene committee institutionalized the intervention by encouraging all members to contribute to detergent costs, encouraging the formation of habitual handwashing, and disseminating information to the community.

One head teacher at a rural school said: Every work needs to be done through a system, and hygiene committee is such a good system to maintain the promoted activities at school compound.

One head teacher an urban school said: Soapy water requires such minimal amount for which we all (teachers and school management committee members) are paying and can continue funds in future as well.

Maintenance duties for student members of the hygiene committee at three schools and the cleaning staff at one urban school included storing water, preparing soapy water and cleaning all the handwashing stations. Students perceived the pump top soapy water bottle as similar to using liquid soap. However, sometimes the pump became stuck, causing rural school students to miss classes trying to repair the bottles.

One male student of grade 5 from the hygiene committee at a rural school said: We start the school day by cleaning, refilling water, and preparing soapy water; otherwise, students will not be able to wash hands.

Phase 3: Follow-up assessment at 14-months to explore sustainability. During the spot checks of facilities, fieldworkers identified that one urban school stopped using the soapy water bottle, but the remaining schools continued to use them (Table 3).

During the structured observations, fieldworkers observed 1,055 students' opportunities for handwashing: 56\% (586) 
before eating, 44\% (465) after toileting, and 3\% (4) after cleaning the toilet. In the 586 before eating events, $9 \%$ (55) washed both hands with soapy water; 89\% (520) did not wash hands at all. In the 465 after toileting events, 37\% (172) washed both hands with soapy water; $38 \%$ (175) did not wash hands at all (Table 4).

During the qualitative assessment, students who were observed to wash hands reported that handwashing habits with soapy water resulted in fewer diarrheal disease episodes that motivated them to wash their hands, and they disseminated the idea of preparing soapy water to their family members, neighbors and relatives.

One male member of parent-teacher association at a rural school said: My daughter is at grade 4. She told me to arrange soapy water at home for handwashing as it was provided at school. So, I brought liquid soap for her from the market because I don't have the pump or the bottle to prepare soapy water.

Students who were observed not to wash hands, especially in urban schools, reported that they did not wash their hands as they were in hurry to play and the lack of a handwashing station with soapy water demotivated them.

Teachers, management committee members and janitors at urban schools commonly mentioned shortages of teachers and janitors, increased workload and inactive management committee members who were reluctant to maintain the handwashing stations and to contribute to the recurrent cost of detergent.

One female janitor at an urban school said: Sometimes I prepare soapy water and sometimes I ignore because male students mostly play with the soapy water bottle. They make bubbles with soapy water, spread it all over the toilet and throw the bottle to other students. This way they finish it. So, I don't want to refill it though teachers told me to do, but how many times I should refill the bucket and the bottle? It becomes difficult for me to clean the toilet and hardware. So, I stored all hardware inside.

One female head teacher at an urban school said: The president of the school management committees is sick, vice president is outside of Bangladesh, and one teacher has been resigned from this school. Our janitor, who was proactive, also died last month and students of grade 5 have finished their studies and left for high schools. Therefore, the hygiene committee became inactive to continue handwashing activities in the school.

Rural schoolteachers, management committee members, and janitors noted that perceived health benefits, active hygiene committee supervision and involvement of students in the maintenance activity had played a vital role in continued use of the handwashing stations and contributions to the recurring costs of detergent.

One male student of grade 5 at a rural school said: Our head teacher always ensured the handwashing facilities were available at school compound. He distributed the overall maintenance responsibilities of the handwashing station to the students of the hygiene committee, so they refilled water in the bucket, prepared soapy water and kept the station clean.

\section{DISCUSSION}

Our baseline data suggested handwashing with soap was not a common practice among school children in
Bangladesh, and almost nonexistent before eating and after toileting. Previous studies suggest that barriers to sustained behavior change of WASH interventions include high cost of products, lack of infrastructure, habit formation, motivation, and maintenance. ${ }^{33,39-41}$ This pilot intervention attempted to address these barriers.

Our study showed that schools found soapy water a lowcost (US\$0.05 per day for daily handwashing in the school) and child-friendly product that created access and opportunities for handwashing practices. The school community commonly credited the increase in handwashing rates to this low-cost hand cleaning agent that transcended the common barriers of bar soap related to high cost (the average price of common bar soap is US\$0.35), theft, and misuse of bar soap in the school. ${ }^{13,42}$

The lack of infrastructure (availability of running water, basin, and soap) to promote handwashing at key times is common in schools in low-income countries including Bangladesh $^{24,43}$ and most of this study's schools. Therefore, soapy water was dispensed as part of the handwashing stations in this study. These handwashing stations provided a complete package of convenient infrastructure and worked as a structural and enabling factor to influence handwashing behavior change. ${ }^{10,44,45}$

Students and teachers indicated that the promotion of handwashing with soapy water was integrated into the school's curriculum using weekly sessions and exams. This suggests that the intervention supported individual psychosocial factors of habit formation related messaging (e.g., key times for handwashing) and establishment of handwashing habits and development of cues or nudges among students that trigger and reinforce habits such as easily accessed handwashing station and visual reminders (e.g., cue cards and hygiene committee). Students also identified perceived health benefits and concerns about disgust and cleanliness as sustained affective motivations for handwashing with soapy water.

Marteen et al. suggested that successful sustained adoption includes 1) the behavior, 2) the frequency of the behavior practice, and 3) the length of time at which this behavior should be measured to be considered sustained. ${ }^{33}$ This intervention achieved sustained adoption. Handwashing with soapy water significantly increased after 30 days of intervention at two key times: before eating (0 to $46 \%, P<$ $0.05)$ and after toileting $(0.7-82 \%, P<0.05)$, that emphasizes the importance of providing essential facilities. ${ }^{46-48}$ Although handwashing behaviors did decline over time, handwashing after toileting with soapy water $(0.7 \%$ versus $37 \%, P$ value $\leq 0.05)$, and handwashing with soapy water before eating (0\% versus $9.4 \%, P$ value $\leq 0.05)$ were still much higher at 14 month than at baseline, suggesting some level of habit adoption. The spot checks and structured observations data from 14 months follow-up also suggest that this handwashing intervention has some potential for sustainability as three of the four schools maintained the handwashing stations stocked with soapy water. This finding contrasts with Kenya and India where schools did not maintain soap at handwashing locations when assessed within a few months or years postintervention. ${ }^{49,50}$ Additionally, teachers and school management committee members in this study continued covering the recurrent cost of detergent even after the project ended in three of the four schools, 
observed at 14 months follow up. Personal attitudes and behaviors of the school leadership may have directly influenced maintenance and behaviors. ${ }^{51-53}$

However, the lack of maintenance a handwashing habit over time might have been affected by the cessation of weekly hygiene sessions (Table 3), inactive management committee members and lack of ongoing availability of essential supplies. Education and provision of materials may be insufficient to ensure long-term adoption of habitual handwashing. Therefore, the long-term success of a school WASH intervention requires a system of school funding with standardized roles and responsibilities for maintenance. ${ }^{54}$ In this pilot intervention, engagement of school communities to form hygiene committees was effective to support operations and maintenance, create champions and promote ownership. It was effective in convincing teachers and school management committee members to cover the recurrent cost of detergent powder for soapy water preparation from the schools' contingency funds (US\$9 per month), ${ }^{25}$ janitors and students ensured maintenance, and students and teachers monitored and motivated handwashing behaviors among students and peers. Having a system in place to cover recurrent costs has the potential for increased intervention sustainability in settings with limited resources. One study conducted in Bangladeshi schools also identified recurrent financial support for operations and maintenance by the government or community, a maintenance plan and a champion (possibly teachers) as important conditions for continued management of school sanitation. ${ }^{25}$ In other contexts, community involvement and support improved accountability of a routine immunization system in Nigeria, 55 in reproductive health outcomes in Malawi, ${ }^{56}$ in public service delivery in India, in detecting maternal deaths in Malawi, ${ }^{57}$ and in funding school sanitation in Bangladesh and Belize. ${ }^{25,58}$ However, a study in Kenya schools found that funding remained a major barrier for sustainable allocation of recurrent costs for soapy water provisions. ${ }^{14}$

The Ministry of Primary and Mass Education increased the school WASH allocation from US\$36.5 million (BDT 2918 million) in 2016-2017 to US\$57.4 million (BDT 4591 million) in 2017-18 financial years for school WASH. ${ }^{59}$ The budget includes financial provision of drinking water supply and sufficient WASH blocks. Each WASH block consists of three toilets, two urinals and hand and foot wash facilities constructed by the Department of Public Health and Engineering (DPHE) through the primary education development project and supported by development partners.

The Ministry of Education allocates up to US\$240US\$370 per school per year under the School Level Improvement Program fund for overall maintenance and school improvements ${ }^{25,60}$ and recommends school management committee and parent teacher associations provide US\$125- US\$625 (BDT 10,000-50,000) (personal communication with the Deputy Director of Planning at Primary Education). Schools can use this recommendation and engage active community members to overcome the weak performance, increase accountability and champion the continued management of school handwashing.

In research among 117 Bangladeshi schools applying a Life Cycle Costs Approach (LCCA), ${ }^{61,62}$ a methodology to estimate future costs, IRC WASH, a nonprofit organization supporting government WASH interventions, estimated
US\$10 (BDT 814) per student is needed to construct water and sanitation facilities in schools, and US\$1.40 (BDT 108) per student per year is needed for recurrent costs of supplies and maintenance of equipment. ${ }^{43}$ Taking the average size of the student body at Bangladeshi schools (700) from a nationally representative survey, ${ }^{28}$ we calculated total US\$395 per school per year is needed particularly for such recurrent costs. However, US\$240-370 allocated under the School Level Improvement Program, is meant to cover several school and educational improvement related expenses and is not specifically allocated for WASH maintenance.

Though the fourth Primary Education Development Program estimated US $\$ 10.5$ million as overall recurrent expenditure for financial years 2019-2023 (that included administration/the salaries for existing teachers and personnel and other recurrent costs), maintenance and supplies for WASH costs are not mentioned. ${ }^{60}$

The Ministry of Education should provide sufficient WASH supplies and include preventive measures linked to handwashing to prevent the rapid spread of communicable diseases like COVID-19 through public schools in Bangladesh. The World Health Organization recommended a soapy water solution, similar to what we deployed in this study, as an alternative hand cleanser to help interrupt the transmission of COVID-19. ${ }^{63}$ Soapy water has been found to be effective as bar soap in removing indicator organisms from hands and is more effective than water alone. ${ }^{42}$ As schools are the potential places for pathogen transmission the feasible and low-cost approaches identified from this study could be promising.

There are some limitations to the conclusions that we can draw from this study. We included only eight schools, though they represented a typical and similar environment to other schools in Bangladesh. The short-term intervention (30 days) might have impacted longer term habit adoption, implying the need for further efforts to improve long-term behavior change. Structured observations by fieldworkers likely altered handwashing practices, though this is a less biased approach to assess hygiene behaviors compared with selfreporting. ${ }^{64,65}$ However, the majority of student did not wash hands with soapy water, hence that presence of an observer likely did not completely alter the targeted practices. This study was conducted in 2012. However, the more recent national hygiene survey conducted in 2018 showed that only $39 \%$ of the school boys and girls had improved, unlocked, accessible toilets that have soap and water available. ${ }^{66}$ Hence the constraints identified in our 2012 study have persisted in Bangladeshi schools.

This study piloted an innovative combination of appropriate technology, knowledge, and skill acquisition interventions to promote handwashing in a school setting. The training of students with targeted communication materials and formation of hygiene committees sought to make handwashing with soap at two key times a sustained change in behavior. Although direct government support for the supplies necessary to maintain handwashing were insufficient, following the intervention hygiene, committees in several schools were able to restock supplies and even 14 months later support some improved practices. Efforts to improve government support for these essential public health supplies should continue, but, in the interim, low-cost infrastructure and hygiene 
committees can contribute to a safer educational environment and safer society.

Received October 10, 2020. Accepted for publication August 18, 2021.

Published online November 29, 2021.

Note: Supplemental appendix, tables, and figures appear at www. ajtmh.org.

Acknowledgments: We acknowledge our fieldworkers, study participants, the school communities, and Mahfuzul Islam, Deputy Director from the Directorate of Primary Education for their support throughout the study period. icddr,b is thankful to the Governments of Bangladesh, Canada, Sweden, and the United Kingdom for providing core/ unrestricted support. icddr,b acknowledges with gratitude the study participants, the dedicated field team, and the school communities.

Financial support: This research protocol/activity/study was funded by the U.S. Agency for International Development USAID.

Disclosures: Protocol number: PR-11020. The opinions expressed by the authors do not necessarily reflect the opinions of the U.S. Agency for International Development (USAID), or the U.S. Government.

Authors' addresses: Farhana Sultana, Leanne Unicomb, Mahbubur Rahman, Shahjahan Ali, Dorothy L. Southern, Dalia Yeasmin, Rouha Anamika Sarkar, Kishor K. Das, and Fosiul Alam Nizame, International Centre for Diarrhoeal Disease Research, Bangladesh (icddr,b), Mohakhali, Dhaka, Bangladesh, E-mails: farhana.sultana@icddrb.org, leanne.unicomb60@gmail.com, mahbubr@icddrb.org, ashahjahan@ icddrb.org, dorothysouthern2016@gmail.com, daliay@icddrb.org, rouha.anamika@gmail.com, kishorisrt@gmail.com, and fosiul@icddrb. org. Peter J. Winch, Johns Hopkins Bloomberg School of Public Health, Baltimore, MD, E-mail: pwinch@jhu.edu. Stephen P. Luby, Stanford University, Stanford, CA, E-mail:sluby@stanford.edu.

This is an open-access article distributed under the terms of the Creative Commons Attribution (CC-BY) License, which permits unrestricted use, distribution, and reproduction in any medium, provided the original author and source are credited.

\section{REFERENCES}

1. Neuzil KM, Hohlbein C, Zhu Y, 2002. Illness among schoolchildren during influenza season: effect on school absenteeism, parental absenteeism from work, and secondary illness in families. Arch Pediatr Adolesc Med 156: 986-991.

2. Marks P, Vipond I, Regan F, Wedgwood K, Fey R, Caul E, 2003. A school outbreak of Norwalk-like virus: evidence for airborne transmission. Epidemiol Infect 131: 727-736.

3. Adams J, Bartram J, Chartier Y, Sims J, 2009. Water, Sanitation and Hygiene Standards for Schools in Low-Cost Settings. Geneva, Switzerland: World Health Organization.

4. Curtis V, Cairncross S, 2003. Effect of washing hands with soap on diarrhoea risk in the community: a systematic review. Lancet Infect Dis 3: 275-281.

5. Bowen A, Ma H, Ou J, Bilhimer W, Long T, Mintz E, Hoekstra RM, Luby S, 2007. A cluster randomized controlled trial evaluating the effect of a hand washing promotion programme in Chinese primary schools. Am J Trop Med Hyg 76: 11661173.

6. Talaat M, Afifi S, Dueger E, El-Ashry N, Marfin A, Kandeel A, Mohareb E, El-Sayed N, 2011. Effects of hand hygiene campaigns on incidence of laboratory-confirmed influenza and absenteeism in schoolchildren, Cairo, Egypt. Emerg Infect Dis 17: 619-625.

7. Roby DE, 2004. Research on school attendance and student achievement: a study of Ohio schools. Educ Res Q 28: 3-16.

8. Pickering AJ, Boehm AB, Mwanjali M, Davis J, 2010. Efficacy of waterless hand hygiene compared with handwashing with soap: a field study in Dar es Salaam, Tanzania. Am J Trop Med Hyg 82: 270-278.
9. Azor-Martínez E, Cobos-Carrascosa E, Gimenez-Sanchez F, Martínez-López JM, Garrido-Fernández P, SantistebanMartínez J, Seijas-Vazquez ML, Campos-Fernandez MA, Bonillo-Perales A, 2014. Effectiveness of a multifactorial handwashing program to reduce school absenteeism due to acute gastroenteritis. Pediatr Infect Dis J 33: e34-e39.

10. Pickering AJ, Davis J, Blum AG, Scalmanini J, Oyier B, Okoth G, Breiman RF, Ram PK, 2013. Access to waterless hand sanitizer improves student hand hygiene behavior in primary schools in Nairobi, Kenya. Am J Trop Med Hyg 89: 411-418.

11. Bloomfield SF, Aiello AE, Cookson B, O'boyle C, Larson EL, 2007. The effectiveness of hand hygiene procedures in reducing the risks of infections in home and community settings including handwashing and alcohol-based hand sanitizers. Am J Infect Control 35: S27-S64.

12. Melnick $H$, Darling-Hammond L, Leung $M$, Yun $C$, Schachner $A$, Plasencia S, Ondrasek N, 2020. Reopening Schools in the Context of COVID-19: Health and Safety Guidelines from Other Countries (Policy Brief). Palo Alto, CA: Learning Policy Institute.

13. Centers for Disease Control and Prevention (CDC), 2021. When and How to Wash Your Hands. Available at: https://www.cdc. gov/handwashing/when-how-handwashing.html. Accessed April 17, 2021.

14. World Health Organization, 2009. Hand Hygiene: Why, How \& When? Available at: https://www.who.int/gpsc/5may/Hand Hygiene_Why_How_and_When_Brochure.pdf. Accessed April 17, 2021.

15. Zhang C, Mosa A, Hayward A, Matthews S, 2013. Promoting clean hands among children in Uganda: a school-based intervention using 'tippy-taps'. Public Health 127: 586

16. Biran A, 2011. Enabling technologies for handwashing with soap: a case study on the tippy-tap in Uganda.

17. Galiani S, Gertler P, Orsola-Vidal A, Ajzenman N, 2014. Promoting handwashing behavior: the effect of large-scale community and school-level interventions. Health Econ 25: 1545-1559.

18. White CG, Shinder FS, Shinder AL, Dyer DL, 2001. Reduction of illness absenteeism in elementary schools using an alcoholfree instant hand sanitizer. J Sch Nurs 17: 248-265.

19. Stebbins S, Cummings DA, Stark JH, Vukotich C, Mitruka K, Thompson W, Rinaldo C, Roth L, Wagner M, Wisniewski SR, 2011. Reduction in the incidence of influenza $A$ but not influenza $B$ associated with use of hand sanitizer and cough hygiene in schools: a randomized controlled trial. Pediatr Infect Dis J 30: 921.

20. Saboori S, Mwaki A, Rheingans $R, 2010$. Is soapy water a viable solution for handwashing in schools? Waterlines 29: 329-336.

21. Amin N, Pickering AJ, Ram PK, Unicomb L, Najnin N, Homaira N, Ashraf S, Abedin J, Islam MS, Luby SP, 2014. Microbiological evaluation of the efficacy of soapy water to clean hands: a randomized, non-inferiority field trial. Am J Trop Med Hyg 91: 415-423.

22. Hammond B, Ali Y, Fendler E, Dolan M, Donovan S, 2000. Effect of hand sanitizer use on elementary school absenteeism. Am $J$ Infect Control 28: 340-346.

23. Sultana F, Nizame FA, Southern DL, Unicomb L, Winch PJ, Luby SP, 2017. Pilot of an elementary school cough etiquette intervention: acceptability, feasibility, and potential for sustainability. Am J Trop Med Hyg 97: 1876-1885.

24. Saboori S, Mwaki A, Rheingans RD, 2010. Is soapy water a viable solution for handwashing in schools? Waterlines 29: 329-336.

25. Chatterley C, Javernick-Will A, Linden KG, Alam K, Bottinelli L, Venkatesh $M, 2014$. A qualitative comparative analysis of well-managed school sanitation in Bangladesh. BMC Public Health 14: 6.

26. Sultana F, Nizame FA, Southern DL, Unicomb L, Winch PJ, Luby SP, 2017. Pilot of an elementary school cough etiquette intervention: acceptability, feasibility, and potential for sustainability. Am J Trop Med Hyg 97: 1876-1885.

27. Nasreen S, Azziz-Baumgartner E, Gurley E, Winch P, Unicomb L, Sharker M, Southern D, Luby S, 2010. Prevalent high-risk respiratory hygiene practices in urban and rural Bangladesh. Trop Med Int Health 15: 762-771. 
28. International Centre for Diarrheal Diseases Research B, WaterAid Bangladesh, Ministry of Local Government Rural Development and Cooperatives, 2014. Bangladesh National Hygiene Baseline Survey: Preliminary Report. Dhaka, Bangladesh.

29. Government of the People's Republic of Bangladesh, 2012. National Hygiene Promotion Strategy for Water Supply and Sanitation Sector in Bangladesh. Available at: https://itn.buet. ac.bd/publications/sector-documents/documents/nhps.pdf. Accessed April 14, 2019.

30. World Health Organization, UN-Water, 2019. National systems to support drinking-water: sanitation and hygiene: global status report 2019: UN-Water global analysis and assessment of sanitation and drinking-water: GLAAS 2019 report.

31. Ahmed CM, Douse M, 2019. Legacies and lessons from two decades of Bangladesh primary education programmes. $J$ Educ Human Devel 8: 114-128.

32. Alam T, 2019. Making School WASH Work for and with Students in Bangladesh. Available at: https://www.waterinteg ritynetw ork.net/2019/12/09/making-school-wash-work-for-and-withstudents-in-bangladesh/. Accessed May 17, 2020.

33. Martin NA, Hulland KR, Dreibelbis R, Sultana F, Winch PJ, 2018. Sustained adoption of water, sanitation and hygiene interventions: systematic review. Trop Med Int Health 23: 122-135.

34. Pridmore P, Bendelow G, 1995. Images of health: exploring beliefs of children using the 'draw-and-write' technique. Health Educ J 54: 473-488.

35. Rollins J, 1990. Childhood cancer: siblings draw and tell. Paediatr Nurs 16: 21-27.

36. Dickin KL, Seim G, 2013. Adapting the Trials of Improved Practices (TIPs) approach to explore the acceptability and feasibility of nutrition and parenting recommendations: what works for low-income families? Matern Child Nutr 11: 897-914.

37. Dreibelbis R, Winch PJ, Leontsini E, Hulland KR, Ram PK, Unicomb L, Luby SP, 2013. The integrated behavioural model for water, sanitation, and hygiene: a systematic review of behavioural models and a framework for designing and evaluating behaviour change interventions in infrastructure-restricted settings. BMC Public Health 13: 1015.

38. Donner A, Klar N, 2010. Design and Analysis of Cluster Randomization Trials in Health Research. Chichester, UK: Wiley.

39. McMichael C, Robinson P, 2016. Drivers of sustained hygiene behaviour change: a case study from mid-western Nepal. Soc Sci Med 163: 28-36.

40. Schell SF, Luke DA, Schooley MW, Elliott MB, Herbers SH, Mueller NB, Bunger AC, 2013. Public health program capacity for sustainability: a new framework. Implement Sci 8: 1-9.

41. Kwasnicka D, Dombrowski SU, White M, Sniehotta F, 2016. Theoretical explanations for maintenance of behaviour change: a systematic review of behaviour theories. Health Psychol Rev 10: 277-296.

42. Amin N, Pickering AJ, Ram PK, Unicomb L, Najnin N, Homaira N, Ashraf S, Abedin J, Islam MS, Luby SP, 2014. Microbiological evaluation of the efficacy of soapy water to clean hands: a randomized, non-inferiority field trial. Am J Trop Med Hyg 91: 415-423.

43. Snehalatha M, Fonseca C, Rahman M, Uddin R, Ahmed M, Sharif A, 2015. School WASH Programmes in Bangladesh: How Much Does It Cost? Applying the Life-Cycle Costs Approach in Selected Upazilas. The Hague, The Netherlands: IRC and BRAC.

44. Chittleborough CR, Nicholson AL, Basker E, Bell S, Campbell R, 2012. Factors influencing hand washing behaviour in primary schools: process evaluation within a randomized controlled trial. Health Educ Res 27: 1055-1068.

45. Devine J, 2010. Beyond tippy-taps: the role of enabling products in scaling up and sustaining handwashing. Waterlines 29: 304-314.

46. Rosen L, Manor O, Engelhard D, Brody D, Rosen B, Peleg H, Meir M, Zucker D, 2006. Can a handwashing intervention make a difference? Results from a randomized controlled trial in Jerusalem preschools. Prev Med 42: 27-32.

47. Bowen $\mathrm{A}, \mathrm{Ma} \mathrm{H}, \mathrm{Ou} \mathrm{J}$, Billhimer W, Long T, Mintz E, Hoekstra RM, Luby S, 2007. A cluster-randomized controlled trial evaluating the effect of a handwashing-promotion program in Chinese primary schools. Am J Trop Med Hyg 76: 1166-1173.
48. Dreibelbis R, Kroeger A, Hossain K, Venkatesh M, Ram PK, 2016. Behavior change without behavior change communication: nudging handwashing among primary school students in Bangladesh. Int $J$ Environ Res Public Health 13: 129.

49. Njuguna V, Karanja B, Thuranira M, Shordt K, Snel M, Cairncross S, Biran A, Schmidt W-P, 2008. The Sustainability and Impact of School Sanitation, Water and Hygiene Education in Kenya. Nairobi, Kenya: UNICEF and IRC International Water and Sanitation Centre.

50. Mathew K, Zachariah S, Shordt K, Snel M, Cairncross S, Biran A, Schmidt W-P, 2009. The sustainability and impact of school sanitation, water and hygiene education in southern India. Waterlines 28: 275-292.

51. Early E, Battle K, Cantwell E, English J, J'Anne EL, Larson E, 1998. Effect of several interventions on the frequency of handwashing among elementary public school children. $A m \mathrm{~J}$ Infect Control 26: 263-269.

52. Monsma M, Day R, St Arnaud S, 1992. Handwashing makes a difference. J Sch Health 62: 109.

53. Muto CA, Sistrom MG, Farr BM, 2000. Hand hygiene rates unaffected by installation of dispensers of a rapidly acting hand antiseptic. Am J Infect Control 28: 273-276.

54. Saboori S, Mwaki A, Porter SE, Okech B, Freeman MC, Rheingans RD, 2011. Sustaining school hand washing and water treatment programmes: lessons learned and to be learned. Waterlines 30: 298-311.

55. Erchick DJ, George AS, Umeh C, Wonodi C, 2017. Understanding internal accountability in Nigeria's routine immunization system: perspectives from Government Officials at the National, State, and Local Levels. Int J Health Policy Manag 6: 403-412.

56. Gullo S, Galavotti C, Sebert Kuhlmann A, Msiska T, Hastings P, Marti CN, 2017. Effects of a social accountability approach, CARE's Community Score Card, on reproductive healthrelated outcomes in Malawi: a cluster-randomized controlled evaluation. PLoS One 12: e0171316.

57. Bayley O, Chapota H, Kainja E, Phiri T, Gondwe C, King C, Nambiar B, Mwansambo C, Kazembe P, Costello A, 2015. Community-linked maternal death review (CLMDR) to measure and prevent maternal mortality: a pilot study in rural Malawi. BMJ Open 5: e007753.

58. Chatterley C, Linden K, Javernick-Will A, 2013. Identifying drivers of sustainable school sanitation in Belize. J Water Sanit Hyg Dev 3: 411-422.

59. Rahman HZ, Wazed MA, Islam MA, 2018. Bangaldesh Analysis on WASH Budget Allocation FY 2017-18. Available at: https:// drive.google.com/file/d/13WvXdgi_Wnj47iLA4Y54ew5x1m2v Yv_Z/view. Accessed October 27, 2019.

60. Asian Development Bank, Board of Directors, 2018. Proposed Results-Based Loan People's Republic of Bangladesh: Supporting Fourth Primary Education Development Program. Available at: https://www.adb.org/sites/default/files/projectdocum ents/50192/50192-002-rrp-en.pdf. Accessed February 22, 2020.

61. Korpi E, Ala-Risku T, 2008. Life cycle costing: a review of published case studies. Manag Audit J 23: 240-261.

62. Fonseca C et al., 2011. Life-Cycle Costs Approach: Costing Sustainable Services. The Hague, The Netherlands: IRC.

63. World Health Organization, 2020. Interim Recommendations on Obligatory Hand Hygiene against Transmission of COVID-19. Available at: https://www.who.int/who-documents-detail/interi $\mathrm{m}$-recommendations-on-obligatory-hand-hygiene-against-trans mission-of-covid-19?fbclid=IwAR1LMiJvtwbZtc3jxvOLFV EGO5o_2ZtPkTYBvTvpGspoV2btVM7eeV4FkTQ. Accessed April 19, 2020

64. Biran A, Rabie T, Schmidt W, Juvekar S, Hirve S, Curtis V, 2008. Comparing the performance of indicators of hand-washing practices in rural Indian households. Trop Med Int Health 13: 278-285.

65. Biran A et al., 2009. The effect of a soap promotion and hygiene education campaign on handwashing behaviour in rural India: a cluster randomised trial. Trop Med Int Health 14: 1303-1314.

66. Bangladesh Bureau of Statistics, 2020. National Hygiene Survey 2018. Dhaka, Bangladesh. 